Chair for Management Sciences and Energy Economics University of Duisburg-Essen

EWL Working Paper No. [01/2014]

\title{
VALUATION OF MULTIPLE HYRO RESERVOIR STORAGE SYSTEMS IN COMPETITIVE ELECTRICITY MARKETS
}

\author{
by \\ Bastian Felix, \\ and \\ Christoph Weber
}

April 2014 


\title{
VALUATION OF MULTIPLE HYRO RESERVOIR STORAGE SYSTEMS IN COMPETITIVE ELECTRICITY MARKETS
}

\author{
by Bastian Felix and Christoph Weber
}

\begin{abstract}
Increasing renewable generation results in growing supply uncertainty. By now hydrostorages are the most efficient way of smoothing uncertain power supply. In liberalized and competitive markets the valuation of hydro storages investment projects needs to take the market information and therefore the uncertainty of electricity prices into account in investment valuation. Besides the in vestment in new pump storage facilities the extension of existing storage sites may be an opportunity. However, the correct valuation of multiple reservoir storage systems within an uncertain market is a valuation problem with high dimensionality. We propose an approach that applies numerically constructed multinomial recombining price trees to reduce the problem dimension. We present results for a representative case study. In doing so, we apply a spot price model which accounts for the price fundamentals as well as for the price stochastic.
\end{abstract}

Keywords : hydroelectric valuation, optimal control, dynamic programming JEL-Classification : L94, C61, Q4

BASTIAN FELIX

Chair for Management Sciences and Energy Economics, University of Duisburg-Essen (Campus Essen)

Universitätsstr. 11, 45117 Essen

++49 - (0)2 01 / 183-2399

www.ewl.wiwi.uni-due.de

bastian.felix@uni-due.de
Prof. Dr. ChRISTOPH WeBER

Chair for Management Sciences and Energy Economics, University of Duisburg-Essen (Campus Essen) Universitätsstr. 11, 45117 Essen ++49 - (0)2 01 / 183-2966 www.ewl.wiwi.uni-due.de christoph.weber@uni-due.de

The authors are solely responsible for the contents which do not necessarily represent the opinion of the Chair for Management Sciences and Energy Economics. 


\section{Introduction}

During the last years, the capacity of renewable power generation increased significantly in Germany. Between 2010 and 2012, the installed wind generation capacity increased by 5 GW up to $31 \mathrm{GW}$. Moreover, photovoltaic generation capacity doubled to $24.6 \mathrm{GW}$ (cf. EEX (2012)). As a consequence, the share of intermittent power generation by wind and photovoltaic increases. Electricity being not storable, demand must nevertheless equal supply at any time instant. To achieve this, conventional, e.g. gas or coal fired, power plants may be ramped up in times with high demand or down if electricity supply exceeds demand. However this approach may fail when facing the possible large hourly gradients of renewable infeed. In contrast, pumped hydro storages can provide the counterpart of this large infeed gradients, as they can be ramped up or down much faster than conventional power plants. Therefore, storages operate their pumps in times with high supply and low demand to pump water in the upside reservoir. This water is released in times with high demand and low supply. By now (pumped) hydro storages are the most efficient possibility to store electricity. According to DENA (2010) pump storages may even enhance grid stability. In 2011, an additional generation capacity of 9 GW was planned or under construction in Austria, Germany, Luxembourg and Switzerland (cf. Vennemann et al. (2011)). An overview of recent developments in Europe and Germany is provided by Vennemann et al. (2011) and Steffen (2012), respectively.

Hydro storages offer flexibility in an uncertain electricity market. The possibility to react flexibly to changing market conditions, e.g. uncertainty of wind infeed, demand, power plant outages, creates an additional value which can be valuated adequately applying real options theory (cf. Dixit and Pindyck (1994)). Applying dynamic programming, Thompson et al. (2004) use real options theory to derive a partial integro-differential equation for the valuation of hydroelectric and thermal power generators in a competitive electricity market. This differential equation is solved with explicit finite differences. Muche (2009) valuates pump storages optimizing the intraday contribution margin by mixed integer programming. Thereby he considers the price uncertainty by MonteCarlo Simulation. This approach may be applied for pumped hydro storages, as most pumped hydro storages have a capacity of less than six full load hours. In fact they were build to realize the peak-offpeak spread. Accordingly they were filled at night, while lignite and nuclear power plants did not ramp down, and emptied at noon. Yet, as extreme wind infeed may last more than six hours, we consider the optimal operation and valuation of a large pumped hydro storage system with natural inflow that can provide pump and or turbine capacity for a longer time horizon.

The optimal operation of reservoir storage systems has been subject of various publications in the 
last decades. Labadie (2004) gives an overview on existing approaches. Thereby the optimal operation of multireservoir may be determined with respect to power production, e.g. Braga Jr. et al. (1991), Pereira et al. (1999). Moreover, Tilmant et al. (2008) and Goor et al. (2011) extend the subject to water resources planning and take irrigation issues into account. Thereby Pereira et al. (1999), Tilmant et al. (2008) and Goor et al. (2011) apply stochastic dual dynamic programming (SDDP) on a cascaded multireservoir system. Applying SDDP to this scheduling problem avoids the curse of dimensionality occurring in dynamic optimization problems. For instance, Pereira et al. (1999) focuses on the minimization of power system costs and gives a brief note on how the algorithm may be modified to maximize spot revenues. Archibald et al. (1997) solves a stochastic dynamic programming model to determine the optimal operation policy of a multireservoir system. Thereby storages are aggregated to reduce the problem dimension. Further approaches on the optimal operation of multireservoir systems may include stochastic differential dynamic programming El-Awar et al. (1998) or mixed integer nonlinear programming Diaz et al. (2011).

The approaches listed above consider the case of cascaded reservoir systems where all flows have the identical flow direction. Considering both flow directions increases the problem dimension significantly. For a cascaded storage system the reservoir level solely depends on the operating decision of the considered reservoir and the turbining decisions of the upper basins. Taking additionally the possibility of pumping into account, the inventory level also depends on the pumping decisions of the lower basins. Moreover these papers focus on the uncertainty of natural inflows. In contrast the paper at hand accounts for bidirectional reservoir interconnection via turbines and pumps. Thereby we focus on the uncertainty of spot prices.

As a consequence to the natural inflow and the size of the reservoir the storage value is path dependent. Hence the operating decision at a considered time instant may affect the inventory level and operating decisions of all subsequent time steps. Thus, the operating decisions at the considered time instant have to take the expected continuation values resulting from exercising the strategy into account. This is called the dynamic programming property of the valuation problem. Emphasizing the relationship to financial option terminology, the reservoir storage offers a bundle of options on the electricity price. These options may be exercised at each arbitrary time step corresponding to an American option type. Therefore, large storages may be considered as bundle of path dependent American options and Monte Carlo Simulation is not suited (cf. Hull (2009)). In particular, applying Monte Carlo Simulation corresponds to the assumption of perfect foresight for each particular price path, resulting in a possible overestimation of the storage value. Path dependent American options may be valuated applying Least-Squares-Monte-Carlo-Simulation (Longstaff and Schwartz (2001), Boogert and de Jong (2008)) or (recombining) price trees (cf. Fe- 
lix and Weber (2012)). Both of these approaches apply the dynamic programming property of the valuation problem: the operating decision is determined taking the expected continuation value after an operating decision into the account. In this paper we apply the approach of Felix and Weber (2012) to the valuation of a reservoir storage system with natural inflow. In doing so, we reduce the high dimensionality of this valuation problem. We thereby focus on the uncertainty of electricity wholesale market prices. As wind infeed and projections affect the market prices we assume the information of wind uncertainty to be included in the market prices.

The remainder of this article is organized as follows: Section 2 introduces the general valuation problem. Afterwards the proposed valuation approach is introduced in section 3. Section 4 describes the applied price model and provides the results of a case study for a representative reservoir storage system. Section 5 concludes.

\section{Mathematical model formulation}

This section develops the valuation model. Thereby the underlying dynamic programming equation is derived and the conditions for an optimal operation of the reservoir storage system are discussed.

We assume a profit maximizing, price taking storage operator. The aim of this storage operator is the maximization of the expected profit resulting from pumping and turbining within the considered valuation period $\left[t_{0}, T\right]$ (cf. Thompson et al. (2004, 2009), Felix and Weber (2012)):

$$
V\left(i, t_{0}, S\left(t_{0}\right)\right)=\max _{c_{m, n}}\left\{\mathbb{E}\left[\int_{t_{0}}^{T}\left(\sum_{\substack{(m, n) \\ \in a(\Phi \times \Phi)}} \eta_{m, n} \xi_{m, n} c_{m, n}^{i, \tau} S(\tau)\right) d \tau\right]\right\}
$$

Here $S$ is the spot price of electricity, $\xi_{m, n}$ is the potential energy between the reservoirs $m$ and $n$ and $\eta_{m, n}$ accounts for the efficiency loss of pumping and turbining. In fact, for turbining $\eta_{m, n}$ equals the efficiency rate. For pumping $\eta_{m, n}$ is the inverse of the efficiency rate of pumping. Furthermore, $\Phi$ denotes the set of considered storages $(\Phi=\{1, \ldots, M\})$ and the set $a(\Phi \times \Phi)$ defines the admissible storage connections. In the following we consider solely $(m, n)$ with $(m, n) \in a(\Phi \times \Phi)$. Given that optimal operations are determined, the storage value results as integral over the sum of all revenues and costs associated with these operations over time. In the following we assume that the reservoirs are uniquely numbered according to their location above sea level (cf. Figure 1). Thereby we assign the lowest number to the storage with the lowest location above sea level. Usually this might be the runoff river which has no reservoir. All reservoirs have significant natural inflow. The operating strategy between storage $m$ and storage $n$ is denoted by $c_{m, n}^{i, t}$, depending 


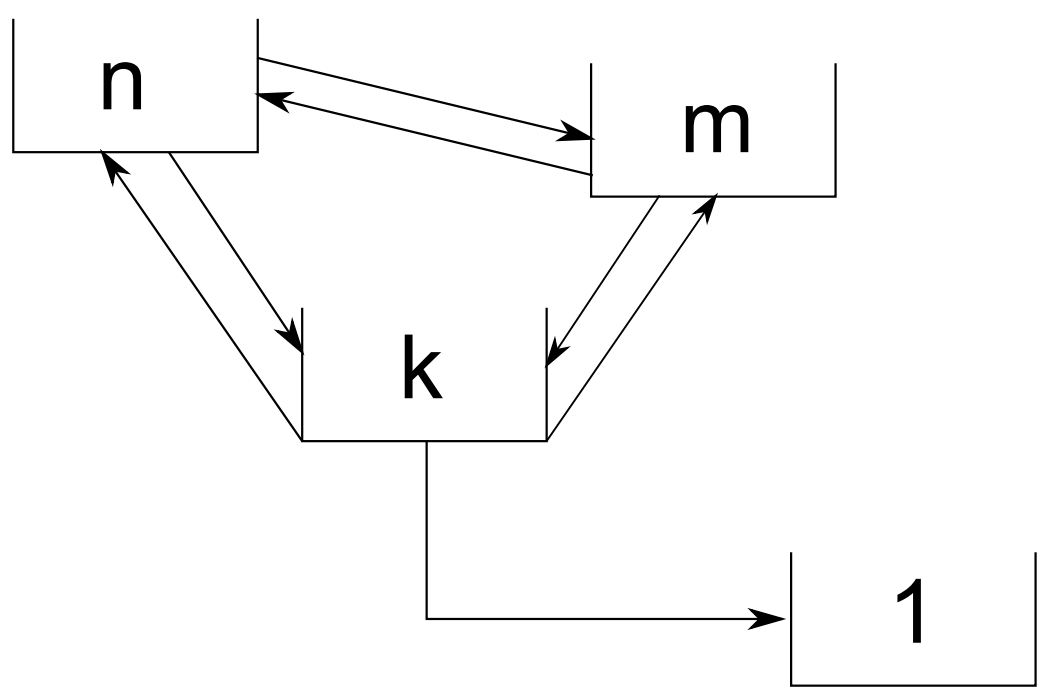

Figure 1: Considered storage reservoir system.

on time $t$, inventory $i=\left(i_{1}(t), \ldots, i_{M}(t)\right)$ and price $S(t)$. Hence, all operations depend on the inventory levels of all reservoirs. The operating strategy $c_{m, n}^{i, t}$ represents pumping for $m<n$ and turbining for $m>n$. Defining $c_{m, n}^{i, t}$ to be negative for pumping and positive for turbining, the storage operations are restricted by technical capacity constraints:

$$
\begin{aligned}
& c_{m, n}^{i, t} \geq \underline{c}_{m, n} \text { for } m<n, \\
& c_{m, n}^{i, t} \leq \bar{c}_{m, n} \text { for } m>n .
\end{aligned}
$$

The maximum heads of the considered storages are assumed to be significantly larger than the differences between the minimum and maximum heads. Thus, inventory dependent capacity constraints are neglected (cf. Tilmant et al. (2008)). However, they can be implemented by adjusting the approach of Felix and Weber (2012) who account for volume dependent injection and withdrawal rates. Applying the storage operations and considering the deterministic natural inflow $z_{m}(t)$, the inventory dynamics for storage $m$ is given by:

$$
d i_{m}=\left(z_{m}+\sum_{n>m}\left(c_{m, n}+c_{n, m}\right)-\sum_{n<m}\left(c_{m, n}+c_{n, m}\right)\right) d t, m=1, \ldots, M
$$

We assume that reservoir spillage is not possible. Thus, inventory levels must not exceed the maximum possible reservoir level $C_{m}, m=1, \ldots, M$. Next, the optimal operating decision rules are 
derived. Therefore equation (1) is reformulated for time step $t$ :

$$
\begin{gathered}
V(i, t, S(t))=\max _{c_{m, n}}\{V(i+d i, t+d t, S+d S) \\
\left.+\int_{t}^{t+d t}\left(\sum_{(m, n)} \eta_{m, n} \xi_{m, n} c_{m, n}^{i, \tau} S(\tau)\right) d \tau\right\} .
\end{gathered}
$$

This is well known as the Bellman equation of dynamic programming. The first term within the brackets is the expected storage value after exercising the storage operations - possibly resulting in new storage inventories $i+d i$. Accordingly a decision at time step $t$ affects the inventory level of all subsequent time steps. This relates to the above considered path dependency of the valuation problem. The second term represents the immediate cash flow resulting from pumping and turbining within the time interval $[t+d t]$.

To derive the optimal operating rules in general, we assume an Itô process as underlying price process:

$$
d S=\mu(S, t) d t+\sigma(S, t) d X,
$$

with drift $\mu(S, t)$, volatility $\sigma(S, t)$ and the increment of a Brownian motion $d X$. Following the arguments in Thompson et al. (2004) - in particular applying a Taylor's Series expansion, Itôs Lemma and taking expectations - equation (5) may be transformed to a partial differential equation. Applying the arguments of Thompson et al. (2009) we write this partial differential equation as follows:

$$
\begin{aligned}
0 & =\max _{c}\left[V_{t}+\frac{1}{2} \sigma^{2} V_{S S}+\mu V_{S}+\sum_{m=1}^{M} z_{m} V_{i_{m}}+S \sum_{(m, n)} \eta_{m, n} \xi_{m, n} c_{m, n}\right. \\
& \left.+\sum_{m=1}^{M} V_{i_{m}}\left(\sum_{n>m}\left(c_{m, n}+c_{n, m}\right)-\sum_{n<m}\left(c_{m, n}+c_{n, m}\right)\right)\right] .
\end{aligned}
$$

In equation (7) $V_{i_{m}}, m=(1, \ldots, M)$ denotes the first partial derivative of the storage value with respect to the inventory of storage $m, \frac{\partial V}{\partial i_{m}}$. To maximize equation (7) it is sufficient to consider the terms including the operation controls (cf. Thompson et al. (2004)). Applying first order conditions to the derivatives with respect to the operation controls one may derive the operating rules easily:

$$
\begin{array}{ll}
\text { for pumping }(m<n): & \eta_{m, n} \xi_{m, n} S \leq V_{i_{n}}-V_{i_{m}}, \\
\text { for turbining }(m>n): & \eta_{m, n} \xi_{m, n} S \geq V_{i_{m}}-V_{i_{n}} .
\end{array}
$$


The optimal operating decisions are determined according to the decision rules (8)-(9). This implies a bang-bang strategy: if pumping/turbining is optimal, the pump/turbine is operated at the maximum possible capacity. This is true under the condition, that the immediate cash flow is linear with respect to the operating variables (cf. Ludkovski and Carmona (2010)). The partial derivatives $V_{i_{m}}, m=(1, \ldots, M)$ can be considered as shadow prices or opportunity costs for an incremental/decremental unit of water in the reservoir. For instance, decision rule (8) may be interpreted as follows: pumping from storage $m$ to storage $n$ is only beneficial if the added value of an additional unit in the upper reservoir two, $\left(V_{i_{n}}-V i_{m}\right)$, exceeds the costs represented by the product of price, potential energy and the inverse of the efficiency rate. The decisions for turbining can be interpreted in perfect analogy.

Partial differential equations like (7) may be solved applying explicit finite differences. However explicit finite differences may demand strong restrictions to the storage inventory, time and price discretization to guarantee stability (cf. Schlüter and Davison (2010)). An approximation by implicit finite differences requires to solve a linear equation system at every time step (cf. Munz and Westermann (2006)). The matrix, which describes this equation system, grows quadratic with the number of price and inventory states.

Limiting the number of considered price states at each time step to a predefined number, the valuation by numerically constructed multinomial recombining trees is an appropriate approach for the valuation of a hydro storage reservoir system. This approach may be easily adapted to a large variety of price processes satisfying the Markov property. Consequently, we apply recombining trees to valuate the reservoir storage system.

In the next section the decision rules derived above are applied in a discrete time and space framework using the recombining tree valuation.

\section{Recombining trees valuation}

This section describes the valuation by recombining trees. The valuation approach is based on a model proposed by Felix and Weber (2012) who valuate natural gas storages applying multinomial recombining trees. We adapt this approach to account for more than one storage basin.

In this section the valuation problem is formulated in discrete time, inventory and price space. Hence, in the following $t$ denotes the t-th time step and $i$ denotes the $\mathrm{i}$-th inventory grid point. Thereby we assume all reservoirs to be discretized with an identical inventory discretization step size $\Delta i$. Accordingly the inventory corresponding to the grid point $i$ may be calculated by the product of $i$ and $\Delta i$. The price discretization at each time step is given by the recombining tree 
which is in general not equidistant in the price dimension.

The recombining tree is constructed based on a set of price simulations (cf. Weber (2005)). These price simulations are aggregated to a predefined number $K$ of price nodes $s_{k}^{t}, k \in\{1, \ldots, K\}$ at each time step $t$. The clustering algorithm assigns each singular price path at each time step to an unique cluster. For instance the clusters may be determined applying the k-means algorithm (cf. Lloyd (1982)) using squared Euclidean distances (cf. Felix and Weber (2012)). The transition probabilities of the clusters at adjacent time steps $P_{t r}\left(s_{k}^{t}, s_{k^{\prime}}^{t+1}\right)$ and the unconditional probabilities $P_{c l}\left(s_{k}^{t}\right)$ at each time step are determined simultaneously with the clustering. Using the cluster assignments, the probability of each price cluster $k$ is computed by calculating the number of price paths $n_{s_{k}^{t}}$ assigned to this price cluster and relating it to the total number of simulations $N$ (cf. Weber (2005), Felix and Weber (2012)):

$$
P_{c l}\left(s_{k}^{t}\right)=\frac{n_{s_{k}^{t}}}{N}
$$

Defining $n_{s_{k}^{t}, s_{k^{\prime}}+1}$ as the number of price paths assigned to cluster $k$ at time step $t$ and to cluster $k^{\prime}$ at time step $t+1$, the transition probabilities are calculated as follows:

$$
P_{t r}\left(s_{k}^{t}, s_{k^{\prime}}^{t+1}\right)=\frac{n_{s_{k}^{t}, s_{k^{\prime}}^{t+1}}}{n_{s_{k}^{t}}}
$$

As the recombining tree is based on a set of price simulations, the underlying price process can be easily adapted. Thereby the underlying price process solely has to fulfill the Markov property - i.e. the last observed price includes all information of the future price distribution. (cf. Felix and Weber (2012))

Applying the recombining price tree to the dynamic programming problem (cf. (5)) we obtain:

$$
V\left(i, t, s_{k}^{t}\right)=\max _{c_{m, n}}\left\{h^{i, t}\left(s_{k}^{t}\right)+\mathbf{E}\left[V\left(i^{\prime}, t+1, s^{t+1}\right) \mid s_{k}^{t}\right]\right\} .
$$

The first term within the brackets represents the immediate cash flow resulting from pumping and turbining at time step $t$ :

$$
h^{i, t}\left(s_{k}^{t}\right)=\sum_{(m, n)} \eta_{m, n} \xi_{m, n} c_{m, n}^{i, t} s_{k}^{t}
$$


The second term is the expected storage value after exercising the storage operations - possibly resulting in new storage inventories $i^{\prime}$ (cf. equation (5)):

$$
\mathbb{E}\left[V\left(i^{\prime}, t+1, s^{t+1}\right) \mid s_{k}^{t}\right]=\sum_{k^{\prime}=1}^{K} P_{t r}\left(s_{k}^{t}, s_{k^{\prime}}^{t+1}\right) V\left(i^{\prime}, t+1, s_{k^{\prime}}^{t+1}\right)
$$

Thereby the expectation is conditioned on the considered and (at the considered time step) known price node $s_{k}^{t}$. The optimal operating strategies are determined applying the decision rules (8)-(9). Therefore the partial derivatives with respect to the inventory have to be computed. For instance, for pumping the partial derivatives are approximated as expected incremental value:

$$
V_{i_{m}}\left(i, t, s_{k}^{t}\right)=\sum_{k^{\prime}=1}^{K} P_{t r}\left(s_{k}^{t}, s_{k^{\prime}}^{t+1}\right)\left(V\left(i^{\prime}, t+1, s_{k^{\prime}}^{t+1}\right)-V\left(i, t+1, s_{k^{\prime}}^{t+1}\right)\right) .
$$

with $i^{\prime}=\left(i_{1}, \ldots, i_{M}\right)+e^{i_{m}}$ and $e^{i_{m}}$ the $i_{m}-t h$ unit vector in $\mathbb{R}^{M}$. The shadow prices for turbining are determined similarly.

Applying the decision rules (8)-(9) in discrete time and space together with scarce reservoir capacity or water in the reservoirs, it may not be possible to apply all operating decision which fulfill (8)-(9). If the reservoir capacity constraints are not limiting after exercising all optimal operations during a time step, all optimal operations can be executed. Though, if one or more of the reservoir capacity constraints become binding during a time step, applying a fixed exercise order may lead to suboptimal results. Hence, the optimization rules rather need to be exercised according to the order of their added value. Therefore we proceed iteratively at each time step: For each price cluster and inventory combination, the optimal operations with the highest added value at the beginning of the time step are selected first. Afterwards the inventories of all reservoirs are adjusted according to the selected operating strategy and the algorithm proceeds with the second best operation. This is done iteratively until either all strategies with positive added value are selected or the inventory capacity constraints are binding.

As described above, the inventories of all storages are discretized on an equidistant inventory grid. Moreover, we permit natural inflow and operating decisions which are not a multiple of the discretization steps. As a consequence, the inventory levels may fall in between the inventory grid points. Therefore, the shadow prices and storage values are interpolated after natural inflow and operating decisions. To interpolate the shadow prices at the end of a time step we set:

$$
\tilde{i}_{m}(t)=i_{m}(t)+\frac{1}{\Delta i}\left(z_{m}(t)+\sum_{n>m}\left(c_{m, n}+c_{n, m}\right)-\sum_{n<m}\left(c_{m, n}+c_{n, m}\right)\right),
$$


as the inventory of storage $m$ at the end of a time step;

$$
\tilde{i}_{m}^{u}(t)=\left\lceil\tilde{i}_{m}(t)\right\rceil,
$$

as the upper bound to the inventory level at the end of a time step;

$$
\tilde{i}_{m}^{d}(t)=\left\lfloor\tilde{i}_{m}(t)\right\rfloor
$$

as the corresponding lower bound and

$$
f_{m}^{d}(t)=\tilde{i}_{m}^{u}(t)-\tilde{i}_{m}(t)
$$

as the weight corresponding to the lower bound. Furthermore we define the set of possible storage states at the end of a time step as Cartesian product:

$$
A^{\prime}=\prod_{m=1}^{M} A_{m}^{\prime} \text { with } A_{m}^{\prime}=\left\{\tilde{i}_{m}^{u}(t), \tilde{i}_{m}^{d}(t)\right\}
$$

The vector $a^{\prime}=\left(a_{1}^{\prime}, \ldots, a_{M}^{\prime}\right)$ is called a vector element of $A^{\prime}$. Together with the following mapping function:

$$
g\left(a_{m}^{\prime}\right)= \begin{cases}f_{m}^{d}(t), & \text { if } a_{m}^{\prime}=\tilde{i}_{m}^{d}, \\ \left(1-f_{m}^{d}(t)\right), & \text { else, }\end{cases}
$$

the shadow price at the end of the time step $t$ is interpolated as follows:

$$
V_{i_{m}}\left(i, t, s_{k}^{t}\right)=\sum_{a^{\prime} \in A^{\prime}} \prod_{m=1}^{M} g_{m}\left(a_{m}^{\prime}\right) V_{i_{m}}\left(a^{\prime}, t, s_{k}^{t}\right)
$$

with $a^{\prime}=\left(a_{1}^{\prime}, \ldots, a_{M}^{\prime}\right)$ and $A^{\prime}$ as defined by equation (20). The interpolation of the storage value after natural inflow, turbining and pumping is done analogously. Due to the recursive structure of (12) the algorithm starts at the last time step with a given salvage value.

\section{Application}

This section applies the recombining tree approach to valuate the large Austrian reservoir storage system Sellrain-Silz and analyzes the benefits of a possible extension of the system.. 
Table 1: Storage characteristics (Parameter data source: TIWAG (2011),TIWAG (2011b), Engel and Faulhaber (2012).

\begin{tabular}{cccc}
\hline Type & Name & $\begin{array}{c}\text { Capacity } \\
{[\mathrm{MW}]}\end{array}$ & $\begin{array}{c}\text { Potential Energy } \\
{\left[\mathrm{MWh} / 1000 \mathrm{~m}^{3}\right]}\end{array}$ \\
\hline Turbine & $c_{4,2}$ & 289 & 0.90 \\
Turbine & $c_{3,2}$ & 130 & 0.52 \\
Turbine & $c_{2,1}$ & 500 & 2.96 \\
Pump & $c_{2,4}$ & 289 & 0.90 \\
Pump & $c_{2,3}$ & 130 & 0.52 \\
\hline & Name & Capacity & Natural Inflow \\
& & {$\left[10^{6} \mathrm{~m}^{3}\right]$} & {$\left[10^{6} \mathrm{~m}^{3} / \mathrm{a}\right]$} \\
\hline Storage 1 & Runoff river & - & - \\
Storage 2 & Längental & 3 & 153.4 \\
Storage 3 & Kühtai & 31 & 74.5 \\
Storage 4 & Finstertal & 60 & 6 \\
\hline
\end{tabular}

\subsection{Test System}

The Sellrain-Silz hydro storage system currently consists of two reservoirs plus the river Inn as drain. The upper reservoir, Finstertal, has a capacity of 60 million cubic meters and the lower basin, Längental, has a total capacity of 3 million cubic meters. Moreover, the lower reservoir can turbine to the runoff river Inn. Both reservoirs have natural inflow. Whereas the natural inflow of the storage basin Finstertal is small relative to the reservoir capacity (6 million cubic meters per annum) the storage Längental has a total inflow of 153.4 million cubic meters per year. This natural inflow corresponds to an generation potential of $475 \mathrm{GWh}$. TIWAG plans to extend this pump storage by a third basin, Kühtai II, resulting in a reservoir storage system as depicted in Figure 2. Accordingly we consider a storage system with two upper reservoirs, one lower reservoir and reservoir one indicating the runoff river. The natural inflow to reservoir three adds 258 GWh of generation potential to the storage system. The characteristics of the storage systems are summarized in Table 1.

We approximate the inflow using daily river discharges published by the Austrian government (cf. eHYD (2013)). For reservoir two this yields the inflow distribution shown in Figure 3. Thereby data from the years 1981-2010 are used to smoothen out stochastic fluctuations.

To account for the market fundamentals we choose a hybrid price model. Thereby we apply the approach proposed by Woll and Weber (2011): In a first step, the electricity prices are analyzed with respect to the deterministic fundamental price drivers. Therefore a daily merit order is constructed based on daily variable cost for each power plant class. The intersection of this merit order with the residual load (the difference of the total load and the renewable infeed) is computed - resulting in hourly fundamental prices. Subsequently the residuals (observed price minus the 


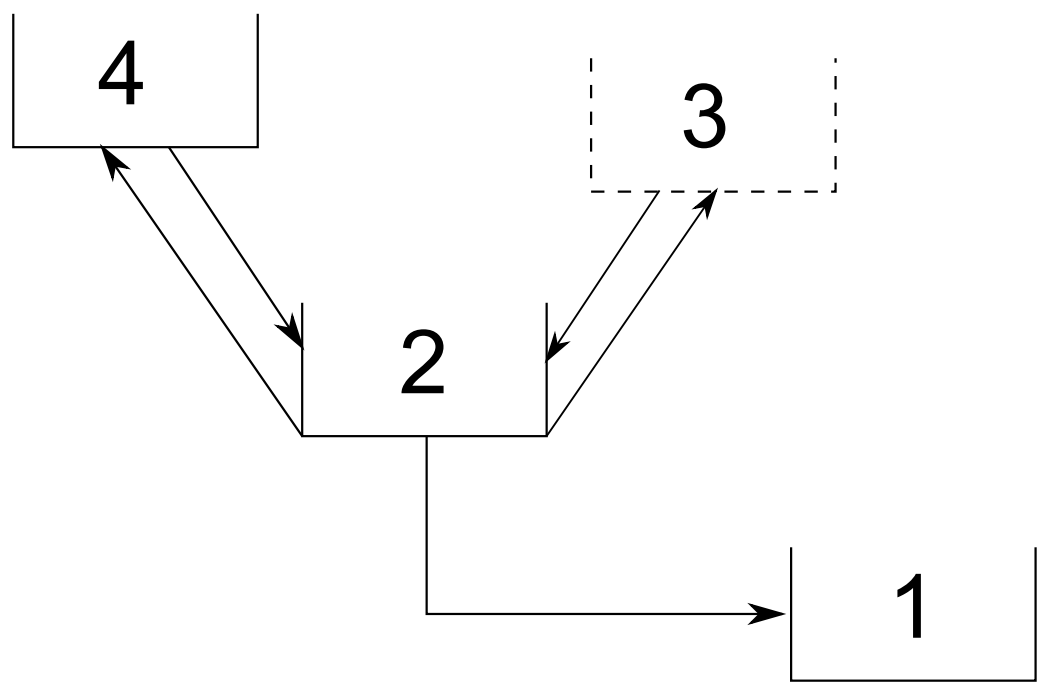

Figure 2: Scheme of the considered storage reservoir system Sellrain-Silz.

fundamental price) are modeled stochastically as described in Weber (2007). In the second step the simulation is done in inverse order with forecast data.

Applying the simulation model to data of 2010, we simulate one thousand price paths. To account for the construction time, the valuation horizon starts with a delay and the year 2015 is considered as valuation period. Therefore, the resulting simulations are calibrated to 2015 applying futures prices. These price paths are aggregated to 30 clusters at each time step to construct the recombining tree.

\subsection{Results}

In a first step we evaluate the value sensitivity with respect to the inventory discretization for the four reservoir storage system. ${ }^{1}$ We find that halving the discretization step size from 750 thousand cubicmeters to 375 thousand cubicmeters per step leads to a value change of 0.3 percent while simultaneously increasing the computational time by a factor of more than six. In the following we thus apply a storage volume discretization of 750 thousand cubicmeters per discretization step resulting in 4 steps for storage two, 80 steps for storage four and 41 discretization steps for storage three. Consequently almost $4 \cdot 10^{5}$ decision variables need to be determined at each time step. Halving the step size, the number of decision variables would increase by a factor eight. This makes clear that due to the large number of decision variables the correct valuation of a hydro storage system including inflow is still a challenging problem within the context of operations research.

Applying an inventory discretization of 750 thousand cubicmeters per step we calculate a value

\footnotetext{
${ }^{1}$ All calculations are computed in MATLAB. ${ }^{\circledR}$
} 


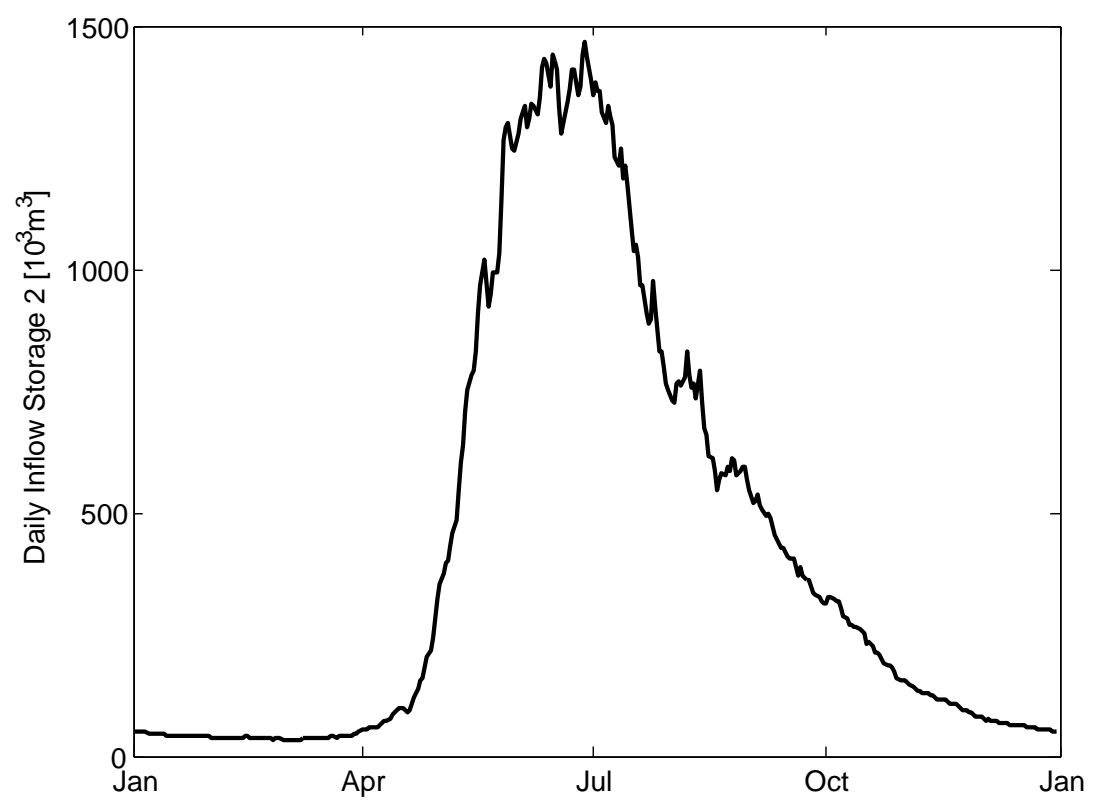

Figure 3: Inflow distribution of storage 2.

of 61.5 million Euro for the initial storage system (without reservoir 3). Relating this to the value of the extended reservoir storage system, the extension of the storage results in an incremental value of 33 million Euro, which is an increase by 54 percent.

Thereby a major part of the incremental storage value results from the additional natural inflow: Multiplying the mean price simulation with the generation potential of the natural inflow we obtain 28.9 million Euro for the two reservoir storage and 44.5 million Euro for the three reservoir storage system. This corresponds to an increase of more than 54 percent. Furthermore, the increase of natural inflow accounts for more than 47 percent of the total incremental value of the three reservoir system. Moreover, natural inflow accounts for a value share of more than 47 percent for the two reservoir as well as for the extended storage system. This emphasizes the relevance of the inflow of the catchment area to the storage value. This becomes even more important in times with an eroding peak-offpeak spread - as currently observed in continental Europe.

To account for the uncertainty of natural inflow, the storage values of the extended system are calculated for two additional scenarios: Increasing and decreasing the natural inflow by one standard deviation, we consider one low and one high inflow scenario. Thereby the standard deviation is calculated considering the distribution of the natural inflows of the years 1981-2010. In doing so, we obtain a storage value of 88.5 million Euro for the lower inflow scenario and a storage value of 101.0 million Euro for the upper inflow scenario. This corresponds to a value increase of 6.9 percent and a decrease of 6.3 percent, respectively.

The decision rules, derived by the backward optimization are applied in a forward simulation. 

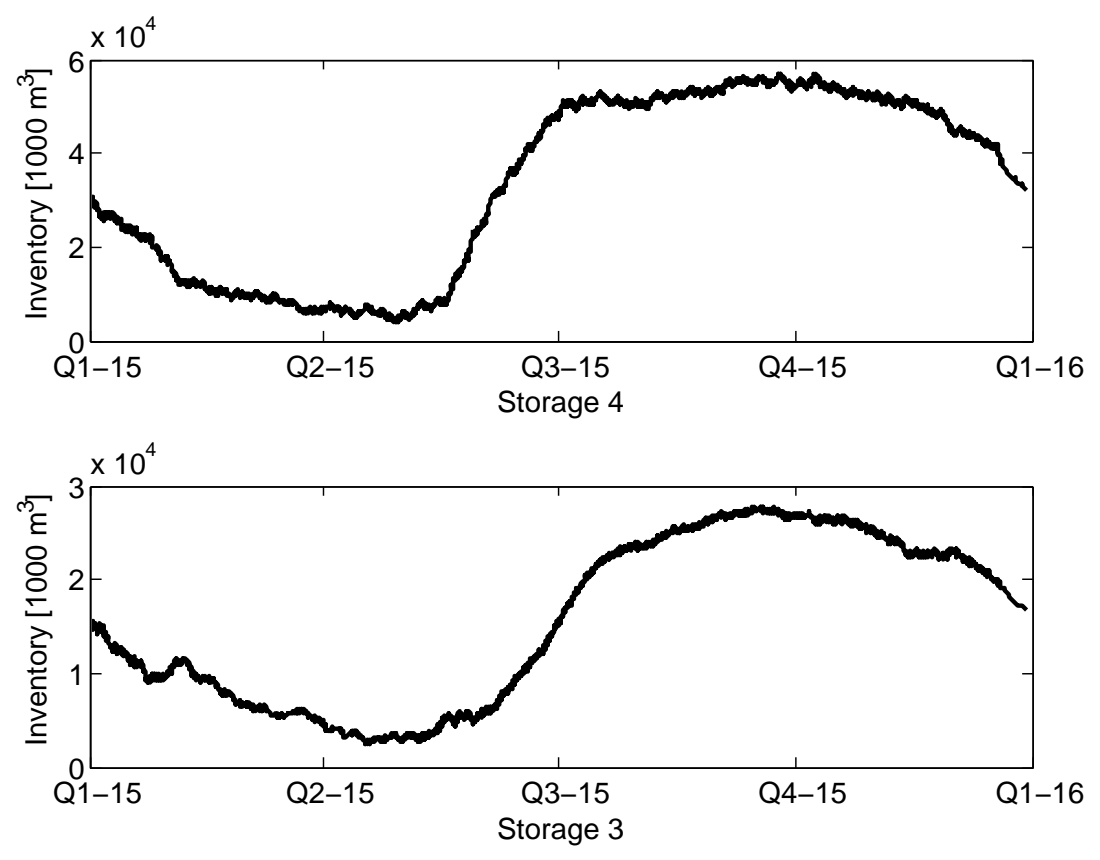

Figure 4: Historical Scheduling/ Forward Simulation.

Thereby we start with a storage level of fifty percent in January. This inventory level corresponds to the average storage inventory level at the begin of the January in the years 2009-2011 (cf. EControl (2011)). For the forward simulation we have to guarantee the continuation principle: i.e. that the storage inventories at the end of the time horizon are equal or above the inventory levels at the first valuation day. For the case of the forward simulation we therefore introduce a penalty function in the backward optimization. Thereby all inventory levels at the last time step which are below the inventory level of the first valuation day (i.e. fifty percent) are penalized with large costs. Applying the decision rules of the backward induction, we determine the optimal inventory trajectories for twenty exemplary price paths. The mean storage inventories of storage four and three are shown in Figure 4 (as the inventory of storage two is filled/ emptied on a high frequency, it is not shown in this Figure).

Besides the mean storage inventory the mean full load hours are determined. These are given in Table 2. Accordingly the water is mostly pumped to storage four. This may be explained by the scarcity of natural inflow in this storage and the higher potential energy of the reservoir four. Considering the full-loadhours for pumping and turbining into and out of storage three, we have to account for the efficiency losses of the pump. As we apply a efficiency rate of 75 percent for the pumps, 968 full-loadhours of pumping correspond to 726 full-loadhours of turbining. The remaining full-loadhours of the turbine result from the natural inflow.

In this case study we have focused on the determination of the optimal cash flow for one repre- 
Table 2: Mean full load hours resulting from the forward simulation.

\begin{tabular}{ccccc}
\hline$c_{2,1}$ & $c_{2,4}$ & $c_{2,3}$ & $c_{4,2}$ & $c_{3,2}$ \\
\hline 1018 & 1883 & 968 & 1423 & 1021 \\
\hline
\end{tabular}

sentative year. For the valuation over the total economic lifetime one has to couple the short term spot price model with a (stochastic) long-term fundamental market model. Applying the resulting price scenarios to the valuation model and discounting the cash flows one obtains the net present value of the investment.

\section{Conclusion}

In this paper we apply the valuation by recombining trees to a multiple reservoir storage system with natural inflow and show that this approach may help to cope with the curse of dimensionality. Thereby the particular problems of the implementation of the valuation, like interpolating the shadow prices or determining the optimal sequence of operating decisions are pointed out. The proposed valuation approach is applied to a representative case study. Further research may focus on the realization and hedging of the calculated storage values.

\section{References}

Archibald, T., McKinnon, K., and Thomas, L. (1997): An aggregate stochastic dynamic programming model of multireservoir systems. In: Water Resources Research 33 (2), pp. 333-340.

Boogert, A. and de Jong, C. (2008): Gas Storage Valuation Using a Monte Carlo Method. In: The Journal of Derivatives 15 (3), pp. 81-98.

Braga Jr., B., William, W., Becker, L., and Barros, M. (1991): Stochastic Optimization of Multiple-ReservoirSystem Operation. In: Journal of Water Resources Planning and Management 117 (4), pp. 471-481.

DENA (2010): Analyse der Notwendigkeit des Ausbaus von Pumpspeicherwerken und anderen Stromspeichern zur Integration der erneuerbaren Energien. http://www.dena.de/fileadmin/user_upload/Projekte/ Energiesysteme/Dokumente/Endbericht_PSW_-_Integration_EE_dena.pdf, Lastchecked: 2013-0513.

Diaz, F., Contreras, J., Munoz, J., and Pozo, D. (2011): Optimal Scheduling of a Price-Taker Cascaded Reservoir System in a Pool-Based Electricity Market. In: IEEE Transactions on Power Systems 26 (2), pp. 604-615.

Dixit, A. K. and Pindyck, R. S. (1994): Investment under Uncertainty. Princeton, New Jersey: Princeton University Press. 
E-Control (2011): Speicherinhalte zum Monatsletzten. http://www.e-control.at/portal/pls/portal/portal.kb_ folderitems_xml.redirectToltem?pMasterthingld=2225365, Lastchecked: 2012-11-21.

EEX (2012): $\quad$ European Energy Exchange, Installierte Erzeugungskapazität < 100 MW. http://www.transparency.eex.com/de/daten_uebertragungsnetzbetreiber/stromerzeugung/ installierteErzeugungskapazität<100MW, Lastchecked: 2013-05-03.

eHYD (2013): eHYD - Der Zugang zu hydrografischen Daten Österreichs. Messstelle: Kühtai, HZB-Nummer: 202093, http://ehyd.gv.at/, Lastchecked: 2013-03-27.

El-Awar, F., Labadie, J., and Ouarda, T. (1998): Stochastic differential dynamic programming for multireservoir system control. In: Stochastic Hydrology and Hydraulics 12 (4), pp. 247-266.

Engel, A. and Faulhaber, J. (2012): Kraftwerksgruppe Sellrain-Silz. http://www.fh-mainz.de/fileadmin/ content/fb1/pdf/Bau/Exkursionen/Kraftwerksgruppe_Sellrain-Silz.pdf, Lastchecked: 2012-09-25.

Felix, B. and Weber, C. (2012): Gas Storage Valuation Applying Numerically Constructed Recombining Trees. In: European Journal of Operational Research 216 (1), pp. 178-187.

Goor, Q., Kelman, R., and Tilmant, A. (2011): Optimal Multipurpose-Multireservoir Operation Model with Variable Productivity of Hydropower Plants. In: Journal of Water Resources Planning and Management 137 (3), pp. 258-267.

Hull, J. C. (2009): Options, Futures, and other Derivatives (6 ed.). Upper Saddle River, New Jersey: Prentice Hall.

Labadie, J. (2004): Optimal operation of multireservoir systems: State-of-the-art review. In: Journal of Water Resources Planning and Management 130 (2), pp. 93-111.

Lloyd, S. (1982): Least squares quantization in PCM. In: IEEE Transactions on Information Theory 28 (2), pp. 129-137.

Longstaff, F. and Schwartz, E. (2001): Valuing American Options by Simulation: A simple Least-Squares Approach. In: Review Of Financial Studies 14 (1), pp. 113-147.

Ludkovski, M. and Carmona, R. (2010): Valuation of Energy Storage: An Optimal Switching Approach. In: Quantitative Finance 10 (4), pp. 359-374.

Muche, T. (2009): A real option-based simulation model to evaluate investments in pump storage plants. In: Energy Policy 37 (11), pp. 4851-4862.

Munz, C. and Westermann, T. (2006): Numerische Behandlung gewöhnlicher und partieller Differenzialgleichungen. Berlin, Heidelberg, New York: Springer.

Pereira, M. V. F., Campodonico, N., and Kelman, R. (1999): Application of Stochastic Dual DP and Extensions to Hydrothermal Scheduling. PSRI Technical Report 012/99.

Schlüter, S. and Davison, M. (2010): Pricing an European gas storage facility using a continuous-time spot price model with GARCH diffusion. IWQW discussion paper series, No. 02/2010. https://www. econstor.eu/dspace/bitstream/10419/30184/1/621625825.pdf, Lastchecked: 2013-05-07. 
Steffen, B. (2012): Prospects for pumped-hydro storage in Germany. In: Energy Policy 45, pp. 420 - 429.

Thompson, M., Davison, M., and Rasmussen, H. (2004): Valuation and Optimal Operation of Electric Power Plants in Competitive Markets. In: Operations Research 52 (4), pp. 546-562.

Thompson, M., Davison, M., and Rasmussen, H. (2009): Natural Gas Storage Valuation and Optimization A Real Options Application. In: Naval Research Logistics 56 (3), pp. 226-238.

Tilmant, A., Pinte, D., and Goor, Q. (2008): Assessing marginal water values in multipurpose multireservoir systems via stochastic programming. In: Water Resources Research 44 (12), pp. W12431.

TIWAG (2011): Kraftwerksbroschüre: Die Kraftwerksgruppe Sellrain Silz.

TIWAG (2011b): Kraftwerk Kühtai II. http://www.tiroler-wasserkraft.at/de/hn/wasserkraftausbau/ speicherkraftwerk_kuehtai/projektvorstellung/index.php, Lastchecked: 2011-09-07.

Vennemann, P., Gruber, K., Haaheim, J., Kunsch, A., Sistenich, H., and Thöni, H. (2011): Pumped storage plants-Status and perspectives. In: VGB PowerTech 4, pp. 32-38.

Weber, C. (2005): Uncertainty in the Electric Power Industry: Methods and Models for Decision Support . New York: Springer.

Weber, C. (2007): Strompreismodellierung - Berücksichtigung empirischer Verteilungen für nichtspeicherbare Güter am Beispiel Elektrizität. In: Essener Unikate 29, pp. 92-101.

Woll, O. and Weber, C. (2011): Hybride Ansätze zur Preismodellierung im Kontext von Portfoliomanagement und Kraftwerksbewertung. In: Optimierung in der Energiewirtschaft, Number 2157 in VDI-Berichte, pp. 93-104. 


\section{Symbols}

\begin{tabular}{ll}
\hline Name & Description \\
\hline Sets & \\
$A^{\prime}$ & Set of possible storages states \\
$\Phi$ & Set of storages \\
$a(\cdot, \cdot)$ & Set of admissible storage connections \\
Parameters & \\
$C_{m}$ & Capacity of reservoir $m$ \\
$K$ & Number of clusters \\
$M$ & Number of storages \\
$\underline{c}_{m, n}$ & Maximum pumping capacity \\
$\bar{c}_{m, n}$ & Maximum turbining capacity \\
$\eta_{m, n}$ & Efficiency rate \\
$f_{m}^{d}$ & weight corresponding to the lower bound $\tilde{i}_{m}^{d}$ \\
$i$ & Storage inventory \\
$\tilde{i}_{m}$ & Inventory of storage $m$ at the end of a time step \\
$\tilde{i}_{m}^{d}, \tilde{i}_{m}^{u}$ & Upper and lower bound to $\tilde{i}_{m}$ \\
$k$ & Cluster index \\
$m, n$ & Storage reservoir index \\
$\mu$ & Drift of stochastic price process \\
$n_{s_{k}^{t}}$ & Number of price paths in cluster $s$ \\
$n_{s_{k}^{t}, s_{k^{\prime}}^{t+1}}$ & Number of price paths in cluster $s$ at $t$ and $s^{\prime}$ at $t+1$ \\
$\sigma$ & Volatility of stochastic price process \\
$\xi_{m, n}$ & Potential energy \\
$t$ & Time index \\
$t_{0}, T$ & Start/End of valuation horizon \\
$z_{m}$ & Inflow in reservoir $m$ \\
$V_{t a r i a b l e s}$ & \\
$P_{t r}$ & Transition probability \\
$P_{c l}$ & Cluster probability \\
$S$ & Spot price \\
$V$ & Storage value \\
$V_{t}$ & first partial derivative with respect to time $t$ \\
$V_{S}, V_{S S}$ & First/Second partial derivative with respect to price $S$ \\
$V_{i_{m}}$ & First partial derivative with respect to the inventory of reservoir $m$ \\
$c_{m, n}^{i, n}$ & Storage operation \\
$h^{i, t}$ & immediate cash flow \\
$s_{k}^{t}$ & Price cluster \\
\hline & \\
\hline
\end{tabular}

